\title{
Prevalence of Hepatitis B Virus Infection in Healthcare Workers of a Tertiary Care Centre in India and Their Vaccination Status
}

\author{
Varsha Singhal, Dhrubajyoti Bora and Sarman Singh* \\ Division of Clinical Microbiology, Department of Laboratory Medicine, All India Institute of Medical Sciences, New Delhi - 110029, India
}

\begin{abstract}
Background: Healthcare Workers have a high risk of occupational exposure to many blood-borne diseases including HIV, Hepatitis B, and Hepatitis C viral infections. Of these Hepatitis B is not only the most transmissible infection, but also the only one that is preventable by vaccination.

Objectives: This study was conducted to estimate the prevalence of Hepatitis B virus infection in healthcare workers (HCWs) employed at the All India Institute of Medical Sciences, New Delhi and to measure protective levels of anti-HBs antibody titre in them.

Methods: A total of 446 Health care workers are grouped in 7 categories according to nature of their work. After ethical clearance and written consent, all health care workers were explained about the objective of the study and were asked to fill a standard questionnaire regarding their personal health information. Their blood samples were tested by Enzyme Linked Immunosorbent assay (ELISA) for Hepatitis B surface antigen and anti-HBs antibody titres.

Results and Interpretation: Out of 446 HCWs, 252 (56.5\%) were vaccinated. In 199 (79\%) of those vaccinated persons, protective levels $(>10 \mathrm{IU} / \mathrm{mL})$ of anti-Hepatitis B surface antigen (anti-HBs) were seen. However, protective levels were also detected in $36(19.35 \%)$ of 186 unvaccinated HCW as natural immunity $(p<0.001)$. The antibody levels were significantly lower in those who were vaccinated more than 5 years ago than those who were vaccinated in last 5 years. Only $2(0.4 \%) \mathrm{HCW}$ s were found to be HBsAg positive. A significant number $(41.7 \%)$ of $\mathrm{HCW}$ are unvaccinated even at this apex health care centre suggesting a need for proactive implementation of HBV vaccination programme.
\end{abstract}

Keywords: Healthcare workers; Hepatitis B virus; Hepatitis B surface antigen; Anti-HBs antibody; HepB vaccine; India

\section{Introduction}

Hepatitis B infection is one of the major public health problems globally and is the tenth leading cause of death. Worldwide, more than two billion of the population have evidence of past or recent HBV infection and there are more than 350 million chronic carriers of this infection [1]. In India, HBsAg prevalence among the general population ranges from 2 to $8 \%$, which places India in an intermediate endemic zone for HBV $[1,2]$.

Occupational exposure of HBV is a well recognized risk for health care workers (HCWs). Throughout the world, millions of healthcare professionals work in health institutions and it is estimated that 600,000 to 800,000 cut and puncture injuries occur among them per year, of which approximately $50 \%$ are not registered [3]. According to $\mathrm{WHO}$, the proportion of health-care workers in the general population varied substantially by region $(0.2 \%-2.5 \%)$, as did the average number of injuries per health-care worker (0.2-4.7 sharps injuries per year). The annual proportion of health-care workers exposed to blood-borne pathogens was $5.9 \%$ for $\mathrm{HBV}$, corresponding to about $66,000 \mathrm{HBV}$ infections in health-care workers worldwide [4].

In developing regions, $40 \%-65 \%$ of HBV infections in health-care workers occurred due to per-cutaneous occupational exposure. In contrast, the fraction of HBV was less than $10 \%$, in developed regions, largely because of immunization and post-exposure prophylaxis [4]. Risk of HBV infection is primarily related to the degree of contact with blood in the workplace and also to the hepatitis B-e antigen (HBeAg) status of the source person. Studies have shown that of the HCWs who sustained injuries from needles contaminated with blood containing $\mathrm{HBV}$, the risk of developing clinical hepatitis is variable from 1-6\% if source is $\mathrm{HBeAg}$ negative to $22-31 \%$ if source is $\mathrm{HBeAg}$ positive
[5,6]. Although most of the HBV infections in healthcare workers are attributed to per-cutaneous exposure, in many studies, most infected HCWs could not recall any overt per-cutaneous injury [7]. In addition, HBV has been demonstrated to survive in dried blood, at room temperature, on environmental surfaces, for at least one week. Thus, HBV infections that occur in HCWs with no history of exposure might have resulted from direct or indirect blood or body fluid exposures that inoculated HBV into the mucosal surfaces or cutaneous scratches and other lesions $[5,6]$. The potential for HBV transmission through contact with environmental surfaces has been demonstrated in investigations of HBV outbreaks among patients and staff of hemo-dialysis units $[8,9]$.

Blood contains the highest HBV titres of all body fluids and is the most important vehicle of transmission in the healthcare settings. HBsAg is also found in several other body fluids, including breast milk, bile, cerebrospinal fluid, feces, nasopharyngeal washings, saliva, semen, sweat, and synovial fluid. However, most body fluids are not efficient vehicles of transmission because they contain low quantities of infectious HBV, despite the presence of HBsAg [7].

Furthermore, despite the availability of Hepatitis B vaccination since

*Corresponding author: Prof. Sarman Singh, Division of Clinical Microbiology, Department of Laboratory Medicine, All India Institute of Medical Sciences, New Delhi - 110 029, India, Phone: +91-11-26588484; Fax: +91-11-26588663; E-mail: sarman_singh@yahoo.com

Received March 14, 2011; Accepted April 21, 2011; Published April 25, 201

Citation: Singhal V, Bora D, Singh S (2011) Prevalence of Hepatitis B Virus Infection in Healthcare Workers of a Tertiary Care Centre in India and Their Vaccination Status. J Vaccines Vaccin 2:118. doi:10.4172/2157-7560.1000118

Copyright: $\odot 2011$ Singhal V, et al. This is an open-access article distributed under the terms of the Creative Commons Attribution License, which permits unrestricted use, distribution, and reproduction in any medium, provided the original author and source are credited. 
1981, a large proportion of Health Care Workers is still unvaccinated. And the condition is same in most of the countries. From India there is very few data available on vaccination status of HCWs. Therefore it is important to know the attitude and awareness of HCWs about Hepatitis B infection, vaccination and post-vaccination immune check-ups.

In the present study, we investigated the prevalence of Hepatitis B and vaccination coverage among HCWs of a tertiary care hospital.

\section{Materials and Methods}

The study was carried out between January 2008 and December 2009 at the All India Institute of Medical Sciences (AIIMS), New Delhi. The study was approved by human ethics committee of the Institute. After written consent, 500 health care workers were counselled in oneto-one manner by a qualified medical doctor and explained about the objective of the study. After that, personal health information of each HCW was recorded using a standard questionnaire and $5 \mathrm{ml}$ blood sample was collected. Volunteers who gave past history of jaundice or any other chronic liver disease, with known HBsAg positive status, patients with documented immune suppression or on prolonged steroid therapy or anti-tubercular treatment and pregnant women were excluded from the study.

Only 54 persons refused to participate in the study hence blood samples and data from 446 apparently healthy health care workers were available. These were grouped into 7 categories according to the nature of their work and duties they perform. The categories include Resident doctors from all disciplines $(n=80)$, Nurses $(n=60)$, Laboratory Technicians $(n=60)$, Hospital Assistants $(n=61)$, Group D staff and laundry workers $(n=60)$, Administrative staff not exposed to clinical

\begin{tabular}{|l|l|l|l|}
\hline & Total & Vaccinated & Unvaccinated \\
\hline N & $446^{*}$ & 252 & 186 \\
\hline Male: Female & $266: 180$ & $120: 132$ & $146: 48$ \\
\hline Age in years (mean \pm SD) & $31.37 \pm 10.68$ & $32.14 \pm 11.03$ & $30.52 \pm 10.03$ \\
\hline $\begin{array}{l}\text { HCW with protective anti- } \\
\text { HBsAg titres (>10 } \mathrm{mlU} / \mathrm{ml})\end{array}$ & 235 & 199 & 36 \\
\hline $\begin{array}{l}\text { HCW without protective anti- } \\
\text { HBsAg titres (<10 } \mathrm{mlU} / \mathrm{ml})\end{array}$ & 203 & 53 & 150 \\
\hline
\end{tabular}

$P$ value $<0.001$

Table 1: Demography and proportion of HCWs having protective antibody titre among those vaccinated and unvaccinated.

\begin{tabular}{|l|l|l|l|}
\hline GROUPS & $\begin{array}{l}\text { Vaccinated, } \\
\mathrm{N}=\text {, (Percentage) }\end{array}$ & $\begin{array}{l}\text { Males vaccinated, } \\
\mathbf{n =} \text { (Percentage) }\end{array}$ & $\begin{array}{l}\text { Females vaccinated } \\
\mathbf{n =} \text { (Percentage) }\end{array}$ \\
\hline 1. Doctors & $76 / 80(95)$ & $52 / 56(92.8)$ & $24 / 24(100)$ \\
\hline 2. Nurses & $46 / 60(76.6)$ & $0 / 3(0)$ & $46 / 57(80.7)$ \\
\hline 3. Technical Staff & $39 / 60(65)$ & $23 / 40(57.5)$ & $16 / 20(80)$ \\
\hline $\begin{array}{l}\text { 4. Assistant Staff } \\
\text { 5. Laundry and } \\
\text { Grade 4 staff }\end{array}$ & $14 / 61(22.9)$ & $14 / 60(23.3)$ & $0 / 1(0)$ \\
\hline $\begin{array}{l}\text { 6. Administrative } \\
\text { Staff }\end{array}$ & $15 / 64(23.4)$ & $15 / 60(25)$ & $0 / 0$ \\
\hline 7. Students & $47 / 61(77)$ & $5 / 5(100)$ & $4 / 22(18.2)$ \\
\hline
\end{tabular}

Table 2: Fraction of vaccinated HCWs gender wise in different groups.

\begin{tabular}{|l|l|l|l|}
\hline & $\begin{array}{l}\text { Group A (vaccination } \\
\mathbf{2} \text { 5 yrs ago) }\end{array}$ & $\begin{array}{l}\text { Group B (vaccination } \\
\text { in last 5 yrs) }\end{array}$ & P value \\
\hline N & $157(62 \%)$ & $97(38 \%)$ & \\
\hline Age in yrs (mean) & 34.12 & 25.36 & \\
\hline $\begin{array}{l}\text { Anti-HBsAg titre in } \\
\text { mlU/ml (mean } \pm \text { SD) }\end{array}$ & $135.44 \pm 110.96$ & $178.27 \pm 102.95$ & $>0.05$ \\
\hline
\end{tabular}

Table 3: Levels of anti-HBsAg antibody titres between Group A and group B. samples $(n=64)$, and Medical and Paramedical students $(n=61)$ who have just admitted into the health care profession.

The personal health information included demographic details of the HCW regarding their age, sex, and occupation, duration of employment, smoking and alcohol history, past history of blood donation or transfusion. Also status of hepatitis B (hepB) vaccination, exposure to blood and/or blood products and the way in which this accident occurred was also recorded. All health care workers were also asked about the use of personal protection devices. From the blood, serum was separated as per standard method in use and tested immediately. In case delay of more than 3 days was imminent, these were stored at $-20^{\circ} \mathrm{C}$ to $-80^{\circ} \mathrm{C}$ and tested within 2 weeks.

\section{Assessment of hepatitis B infection}

HBsAg was done by enzyme linked immune-sorbant assay (ELISA) using commercial kit (Hepanostika HBsAg Ultra kit manufactured by BIOMERIEUX) according to the manufacturer's protocol.

\section{Assessment of anti-HBs titres}

Antibody titres were done by VIDAS Anti HBs Total Quick (HBST) kit in few samples but as cost is prohibitive, rest of the samples were tested by ImmunoLISA HBsAb kit manufactured by ORGANICS. Subjects with anti $\mathrm{HBs}$ titre $>10 \mathrm{mIU} / \mathrm{mL}$ were considered as responders to vaccination, and $<10 \mathrm{mIU} / \mathrm{mL}$ as non-responders.

We divided all vaccinated HCWs into two groups on the basis of completion of their full schedule of vaccination. Group A: those who have completed vaccination before 5 years and Group B: those having received vaccination within last 5 years.

\section{Statistical methods}

The data was managed through SPSS package. Vaccination coverage was calculated as percentage. But as the prevalence of Hep B virus infection among health-care workers was very low, it cannot be calculated in such a small sample size.

\section{Results}

A total of 446 health-care workers were included in this study and out of them 252 (56.5\%) were vaccinated and of them also 224 (88.9\%) were fully vaccinated while $28(11.1 \%)$ were partially vaccinated i.e. they had not completed their full schedule of Hepatitis B vaccination. Most of them had missed their $3^{\text {rd }}$ dose, $186(41.7 \%)$ were not vaccinated at all while $8(1.8 \%)$ were not sure about their vaccination status (Table 1). Among 266 males in study, only 120 (45.1\%) were vaccinated while out of 180 females, $132(73.3 \%)$ were vaccinated (Table 2$)$. Difference in age of vaccinated and unvaccinated HCWs was not significant. Among various groups of the health care workers included in this study the rate of vaccination was very variable as shown in Figure 1 . The study showed that protective levels of anti-HBs antibody $(\geq 10 \mathrm{mIU} / \mathrm{ml})$ were significantly higher [79\% (199 of 252)] in vaccinated than unvaccinated [19.35\% (36 out of 186)] HCWs as shown in Table 1.

Among vaccinated HCWs, 157 (62\%) had received vaccination for $\geq 5$ years ago (Group A) and 97 (38\%) within the last 5 years (Group B). Their demography and difference in anti-HBs antibody titre are shown in Table 3. In group A the antibody titres were significantly lower than in group B as was expected. Only 2 out of $446 \mathrm{HCWs}$ were found to be HBsAg positive. One of them was from sulabh staff and another was a nurse.

All unvaccinated HCWs were prescribed Hepatitis B vaccine and 


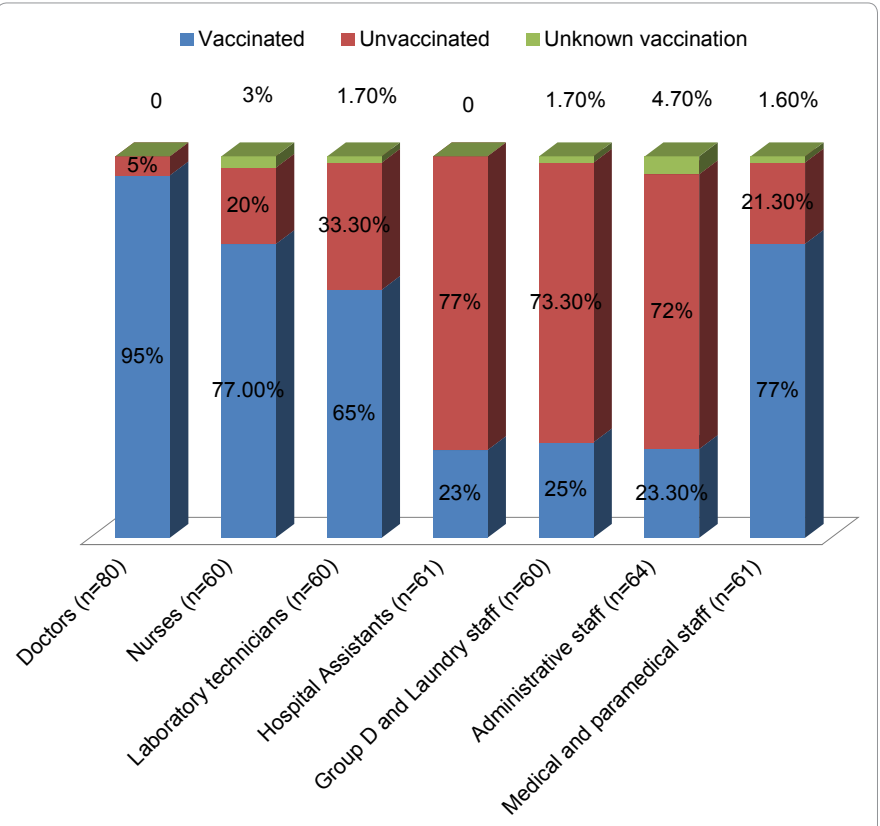

Figure 1: Vaccination status among various groups of health care workers.

were counselled to get checked for serological response after 1 month of full course of vaccination. Also all HCWs who were having anit-HBs titre $<10 \mathrm{mIU} / \mathrm{ml}$ were asked to take booster dose of Hepatitis B vaccine.

\section{Discussion}

This study was conducted in AIIMS which is a tertiary care hospital that makes all HCWs at a greater risk of various blood-borne infections including hepatitis B. Any person who performs tasks involving contact with blood, other body fluids, or sharps contaminated/ smeared with blood should be vaccinated against hepatitis B [10]. The vaccination is effective in protecting against HBV infection in about $90-95 \%$ adults [11]. Estimates of Hepatitis B vaccine coverage among health care workers are needed to calculate the proportion susceptible to $\mathrm{HBV}$ infection. Unfortunately the practice of vaccination is not yet well accepted. According to WHO estimates, Hepatitis B vaccination coverage among health-care workers varies from $18 \%$ being lowest in Africa to highest 77\% in Australia and New Zealand [4].

In our study we found that out of $446 \mathrm{HCWs}, 224$ (50\%) HCWs were fully vaccinated and $28(6 \%)$ had received incomplete vaccination and this proportion of vaccinated HCWs differed in various occupational groups. This estimate of hepatitis B vaccination coverage in health-care workers was consistent with that obtained in the sole study done in G. B. Pant Hospital, Delhi, in which out of 2162 HCWs, 1198 (55.4\%) were vaccinated against Hepatitis B [12]. In another study conducted in Rewa (M. P.), 173 (42.4\%) out of 408 health-care workers had received partial or full course of vaccination against Hepatitis B [13]. This percentage of vaccinated HCWs is much higher as estimated by WHO in South East Asian Region. WHO estimated mean immunization rate of healthcare workers for HBV in SEAR-D region in the absence of data by extrapolating it from AFR-D region where it is $18 \%$ in Nigeria $[4,14]$. It can be explained by the fact that very few reliable studies were available about the hepatitis B vaccine coverage among health-care workers in India before these. And here also this is the data from North India only. This estimate cannot be representative of the country.

Even in most developed countries the situation is not satisfactory.
In United States, according to one study $75 \%$ of HCWs at risk had received 3 or more doses of hepatitis B vaccine [15]. In Sweden, 79\% of HCWs had received at least one dose of vaccine, but only $40 \%$ were reported to be fully vaccinated [16]. In Japan, vaccination coverage was found to be $48.2 \%$ in dental workers [17]

According to our study while among doctors, $96 \%$ were vaccinated, only $23.3 \%$ of administrative staff was vaccinated. This proportion of vaccinated HCWs was more than $65 \%$ among Doctors, Nursing staff, Technical staff and Students while it was less than 25\% among Hospital attendants, Grade 4 \& laundry staff and Administrative HCWs. This difference of vaccination coverage among different groups can be explained on the basis of their educational and awareness status. Doctors, Nurses, Technical staff and Students were comparatively more aware about Hepatitis B and other blood-borne infections and their prevention. Hospital attendants, Grade 4 staff, Laundry workers and administrative staff were least aware about any blood-borne infection including Hepatitis B.

Another interesting finding in our study was difference in vaccination coverage between males and females. Among males, $46 \%$ were vaccinated while among females $74.5 \%$ had received vaccination. This difference may be due to the fact that most of the nursing staff were females while the opposite is true for hospital attendants, sulabh and laundry staff where most of the staff were males. Also, if we see group wise, the difference between male and female vaccination is insignificant (Table 2).

We found another disturbing fact that none of the sulabh staff was vaccinated against hepatitis $B$. This can be explained by the fact that the appointment of sulabh staff in AIIMS is not permanent, so they do not have the facility of Employee Health Scheme (EHS) and also as they belong to low income strata, they cannot afford vaccination by their own. This problem of poor vaccination coverage of HCWs for HBV is not only prevalent in India but in all countries whether developed or developing.

Although few Hepatitis B infection and vaccination coverage studies in health-care workers have been published, the data included in these studies comprised of all health-care workers as one group. Thus, ours is probably the first study of its kind in which we categorized the healthcare workers on the basis of their occupation to see their relation of vaccination coverage and their occupation. The present study is also first study ever carried out in this institute to evaluate the vaccination status of its employees.

In our study, it was seen that out of 252 vaccinated HCWs, 199 (79\%) HCWs were having this protective level $(\geq 10 \mathrm{mIU} / \mathrm{ml})$ of anti-HBs titre and $53(21 \%)$ were having this titre $<10 \mathrm{mIU} / \mathrm{ml}$. This shows that $21 \%$ of vaccinated persons are not sure whether they are responders or nonresponders as for that, they must had done their titre checked only 1-2 months after $3^{\text {rd }}$ dose of Hepatitis $B$ vaccination. So they are still at risk of acquiring Hepatitis B infection and strongly require booster dose of $\mathrm{HBV}$ vaccine. There were $186 \mathrm{HCW}$ who were unvaccinated and 36 $(19.35 \%)$ out of them were also having protective level of antibody titre $(\geq 10 \mathrm{mIU} / \mathrm{ml})$ while rest $150(80.65 \%)$ were having titres $<10 \mathrm{mIU} / \mathrm{ml}$. These results are in concordance with the study done by Lanphear et al. [18] where they found that almost $20 \%$ of unvaccinated HCWs had already acquired natural immunity through previous contact with HBV.

So in our study $46.3 \%$ of all HCWs whether vaccinated or not, were not having protective level of anti-HBs titre so they are not protected against HBV infection. This proportion of unprotected HCW is in accordance with a survey of 2125 surgeons from the US where $38 \%$ 
Citation: Singhal V, Bora D, Singh S (2011) Prevalence of Hepatitis B Virus Infection in Healthcare Workers of a Tertiary Care Centre in India and Their Vaccination Status. J Vaccines Vaccin 2:118. doi:10.4172/2157-7560.1000118

to $50 \%$ of practicing surgeons were not having adequate immunity to HBV although this study was of 1983 [9]. Among HCWs who had protective level of anti-HBs titre; it decreases with the passage of time after vaccination. We divided all vaccinated HCWs in two groups A and B. $62 \%$ of vaccinated HCWs had received their full course of vaccination 5 or more than 5 years back (Group A) and the rest $38 \%$ were vaccinated within last 5 years duration (Group B). Average value of anti-HBs antibody titre in Group A and Group B HCWs was 135.44 $\mathrm{mIU} / \mathrm{ml}$ and $178.27 \mathrm{mIU} / \mathrm{ml}$ respectively. This data shows that the antiHBs titres in HCWs who had been vaccinated at different time frames in the past declines over time. In the study conducted at G. B. Pant Hospital also they showed that median level of anti-HBs titre of HCWs who had received a vaccination more than 5 but less than 10 years ago was $140 \mathrm{mIU} / \mathrm{ml}$, while in those vaccinated in last 5 years, this level was $172 \mathrm{mIU} / \mathrm{ml}$ [12]. In present study, only $2(0.4 \%) \mathrm{HCWs}$ were found to be $\mathrm{HBs} A g$ positive. In the same study mentioned above this percentage was $0.97 \%$. Prevalence of hepatitis B in HCWs in India was 10\% in 1992 according to one study [19] and 2.21\% in a study done in 1998 in Rewa (M.P.) [13]. However, as our study was preliminary one, sample size was small to calculate true prevalence of HBV infection among HCWs.

To summarize, the risk of hepatitis B infection is well documented among healthcare workers. Although with the use of hepatitis B vaccine the incidence of HBV infection in HCWs has decreased, there is still substantial scope for improvement, as many healthcare workers are unvaccinated. Therefore, there is a need for well-planned and clear policies for HBV screening, vaccination and serological response checkups for all healthcare workers, especially those who are at a greater risk of exposure to blood or other potentially infectious material and also there is need for booster dose of $\mathrm{HBV}$ vaccine for those who are already vaccinated but having anti-HBs titre $<10 \mathrm{mIU} / \mathrm{ml}$.

\section{Acknowledgement}

The authors wish to acknowledge the technical help of Mrs Veena Balooni, Mrs. Shalini Singhal, Mrs. Omvati Vats and Mr. Brijesh Kumar. The authors also wish to thank the Medical Superintendent and Registrar, All India Institute of Medical Sciences, New Delhi for their co-operations in the conduct of this study.

\section{References}

1. Previsani N, Lavanchy D. World Health Organization. Hepatitis B (WHO/CDS/ CSR/LYO/2002.2). 2002

2. Gupta S, Gupta R, Joshi YK, Singh S (2008) Role of Horizontal Transmission in Hepatitis B Virus Spread among Household Contacts in North India. Intervirology 51:7-13
3. EPINET (1999) Needlestick prevention devices. Health Devices 28: 381-407.

4. Prüss-Üstün A, Rapiti E, Hutin Y (2005) Estimation of the global burden of disease from sharps injuries to health-care workers. Am J Ind Med 48: 482-490.

5. Werner BG, Grady GF (1982) Accidental hepatitis-B-surface-antigen-positive inoculations: Use of e antigen to estimate infectivity. Ann Intern Med 97: 367369.

6. Lauer JL, VanDrunen NA, Washburn JW, Balfour HH Jr (1979) Transmission of hepatitis B virus in clinical laboratory areas. J Infect Dis 140: 513-516.

7. US Public Health Service (2001) Updated U.S. Public Health Service Guidelines for the Occupational Exposures of HBV, HCV, and HIV and Recommendations for Post-exposure Prophylaxis. MMWR Recomm Rep 50: 1-52.

8. Hennekens $\mathrm{CH}$ (1973) Hemodialysis-associated hepatitis: An outbreak among hospital personnel. JAMA 225: 407-408.

9. Garibaldi RA, Forrest JN, Bryan JA, Hanson BF, Dismukes WE (1973) Hemodialysis-associated hepatitis. JAMA 225: 384-389.

10. Williams WW, Strikas RA, Alter MJ (1997) Immunization of Health-Care Workers: Recommendations of the Advisory Committee on Immunization Practices (ACIP) and the Hospital Infection Control Practices Advisory Committee (HICPAC). MMWR Recomm Rep 46: 1-42.

11. Palmovi ID, Crnjakovic-Palmovic J (1994) Vaccination against hepatitis B Results of the analysis of 2000 population members in Croatia. Eur J Epidemiol 10: 541-547.

12. Sukriti, Pati NT, Sethi A Agrawal K, Agrawal K, et al. (2008) Low levels of awareness, vaccine coverage, and the need for boosters among health care workers in tertiary care hospitals in India. J Gastroenterol Hepatol 23: 17101715

13. Kumar KKA, Baghal PK, Shukla CB, Jain MK (2000) Prevalence of hepatitis B surface antigen (HBsAg) among Health Care Workers. Indian J Comm Med 25: 93-96.

14. Olubuyide IO, Ola SO, Aliyu B, Dosumu OO, Arotiba JT, et al. (1997) Prevalence and epidemiological characteristics of hepatitis B and $C$ infections among doctors and dentists in Nigeria. East Afr Med J 74: 357-361.

15. Simard EP, Miller JT, George PA, Wasley A, Alter MJ, et al. (2007) Hepatitis B Vaccination Coverage Levels among Healthcare Workers in the United States, 2002-2003. Infect Control Hosp Epidemiol 28: 783-790.

16. Dannetun E, Tegnell A, Torner A, Gieseche J (2006) Coverage of hepatitis B vaccination in Swedish healthcare workers. J Hospital Inf 63: 201-204.

17. Nagao Y, Matsuoka H, Kawaguchi T, Ide T, Sata M (2008) HBV and HCV infection in Japanese dental care workers. Intern J Mol Med 21: 791-799.

18. Lanphear BP, Linnemann CC Jr, Cannon CG, DeRonde MM (1993) Decline of clinical hepatitis B in workers at a general hospital: relation to increasing vaccine-induced immunity. Clin Infect Dis 16: 10-14.

19. Elavia AJ, Banker DD (1992) Hepatitis B virus infection in hospital personnel. Natl Med J India 5: 265-268. 